knot gratuitously tied in the tangled skein of physical and psychical phenomena," and while the author "would deprecate the assumption that the psyche has mixed, in any way, as an integral factor in the machinery of the building processes of the forms of life, or in their daily workings as intricate mechanisms," yet he believes that the psyche has been able to exert an influence on the working by either delaying or hastening it. In this the psyche is like Driesch's "Entelechy," which punctuates the transformations of energy within the body.

\section{THE SENSIBILITY OF THE ALIMENTARY} CANAL.

The Goulstonian Lectures on the Sensibility of the Alimentary Canal. Delivered at the Royal College of Physicians on March 14, 16, and 21, I911. By Dr. Arthur F. Hertz. Pp. $\mathrm{v}+80$. (London: Henry Frowde and Hodder and Stoughton, I9Ir.) Price 5 s. net.

THE lectureship which was founded by the late Dr. Goulston is annually awarded to one of the newly elected fellows of the Royal College of Physicians, and so forms a channel by means of which a junior member of the medical profession may make what has often proved to be the first of a valuable series of additions to physiological and pathological progress. Dr. Hertz, however, to whom the honour was awarded this year, is already well known to his medical brethren, and has published many papers on various subjects, as well as a book on constipation. It is to him and his colleagues at Guy's Hospital that we owe the work by means of which the X-ray method has been rendered an aid in medical, as it had been previously shown to be in surgical, cases, and during recent months allusions have been made in these columns to the value of such research in elucidating the disorders of the alimentary canal.

In the present volume, in which Dr. Hertz republishes his lectures, he has, however, struck a new note, and deals with the sensations arising from this part of the body.

The martyr to dyspepsia needs no reminding how insistent such sensations may be. The man in perfect health, however, is scarcely cognisant of the existence of his internal organs. In pre-anæsthetic days, surgeons discovered that the majority of the internal structures of the body are insensitive to touch; they can be handled, and even cut or burnt without causing any sensations. Dr. Hertz not only confirms this by his careful experimental and clinical observations, but has further shown that the alimentary canal is, with the exception of the œesophagus and the anal canal, also insensitive to sensations of heat and cold. Contact with alcohol, however, applied to any part gives rise to a subjective sensation of warmth.

But, as already suggested in the mention of the dyspeptic, pain is experienced; this sensation, which is probably the most primitive of the senses, as it is so important for protective purposes in the struggle for existence can be elicited, but its only cause is NO. 2200 , VOL. 88] tension or stretching, which in a milder degree is also the cause of the sensation of fulness. If disease spreads to, or the tension is exerted on, peritoneal structures, the pain may become excruciating. This sensibility varies in different people, and is most marked in those with an irritable nervous system, as in neurasthenia, hypochondriasis, and anæmia. But when visceral pain or discomfort is present, all people are alike in their inability to localise it accurately. It is then that the so-called "referred pains" come to the assistance of the physician. By this one means that areas of skin and subjacent muscle related to the same spinal segments that govern the viscera, are the seat of discomfort, pain, and even of tenderness. This aspect of the subject has been taken up especially by Dr. Henry Head, and it is quite possible to localise an internal disorder by a study of the referred pain. The painful, tender patch may not always be in the immediate vicinity of the affected organ, for in growth the skin area, and the internal viscus which send their messages to the same segment of the spinal cord may become widely separated; for instance, the association of liver trouble and shoulder pain is familiar even to the non-medical reader.

The alimentary canal, though destitute of any true tactile sense, is endowed with certain sensations peculiar to itself, namely, hunger and thirst. These two sensations do not run quite on all fours with each other, and of them Dr. Hertz refers to hunger only. This consists not only in a general sensation of malaise, but a local sense of abdominal emptiness. Dr. Hertz believes that the latter is produced by the motor activity of the stomach and intestines during fasting; and this affects consciousness partly because the action is excessive, and partly because the central nervous system is over-excitable in this condition.

The brochure of which we have attempted this brief and imperfect summary will amply repay careful perusal, and hearty congratulations are due to its author, not only for his accurate and well-devised experimental work and observations, but also for the lucid and interesting way in which he has presented them.

W. D. H

\section{A NEW PRIMER OF PSYCHOLOGY.}

The Essentials of Psychology. By Prof. W. B. Pillsbury. Pp. xi+362. (New York: The Macmillan Co.; London: Macmillan and Co., Ltd., I9II.) Price 5 s. $6 d$. net.

THE task of writing a good elementary text-book 1 on any science is notoriously arduous, and this is especially the case with so difficult a subject as that of psychology. The ideal writer of such a book would be one whose power of taking a broad and unbiassed view of his subject was guaranteed by a thoroughly sound previous training in mathematics, physiology, and philosophy (metaphysics, logic, ethics, \&c.), every one of which sciences is absolutely essential to a competent knowledge of psychology in its full extent at the present day. A writer falling short of this ideal is likely to betray the fact by an unevenness, more or less pronounced, in his treatment of different parts 